\title{
Investigation on graduate students' social presence and social knowledge construction in two online discussion settings
}

\section{Chen Guo ${ }^{1} \mathbb{D} \cdot$ Peter Shea ${ }^{1} \cdot$ Xiangdong Chen $^{2}$}

Received: 31 May 2021 / Accepted: 16 August 2021 / Published online: 1 September 2021

(c) The Author(s) 2021

\begin{abstract}
Online discussions have become important educational activities through which collaborative learning and knowledge construction can be facilitated. This study explores the use of two online discussion tools, online discussion board and VoiceThread, for supporting online course discussion activities among a group of graduate students and investigates the differences in the levels of social presence and social knowledge construction in the two discussion settings. Meanwhile, the participants' posting behaviors and interaction patterns were also examined. Results reveal that the participants contributed more words when using the audio and video features of VoiceThread. Additionally, the graduate students tended to create more contents and demonstrated more social presence behaviors when interacting with others in the VoiceThread discussion platform. However, the participants exhibited fewer social knowledge construction behaviors than they did in the text-based online discussion board.
\end{abstract}

Keywords Online discussion board $\cdot$ VoiceThread $\cdot$ Social presence $\cdot$ Social knowledge construction

Chen Guo

guochentc@126.com

Peter Shea

pshea@albany.edu

Xiangdong Chen

chen_xiangdong@163.com

1 University at Albany, SUNY, Albany, New York, USA

2 East China Normal University, Shanghai, China 


\section{Introduction}

Online learning is undergoing rapid growth and acceptance at the college level in the United States and now represents a significant proportion of all learning for college students (Shea et al., 2011). A recent report indicates that $72.7 \%$ of undergraduates and $38.7 \%$ of graduate-level students in U.S. public institutions had online course learning experiences (Allen et al., 2016). It is often assumed that in online learning environments, diversely distributed students and instructors can interact and connect as if they were in a shared location via the use of computer-mediated communication tools (Levine, 2007).

Asynchronous online discussion plays a key role in online and blended courses by supporting a variety of educational activities (Gunawardena et al., 2016; Thomas, 2013). It is a useful tool that allows both teachers and students to express their ideas, share personal experiences, and communicate with other peers without the constraint of time and geographic location (Gao et al., 2013; Johnson, 2008). However, not all students can succeed and feel comfortable while communicating and interacting with others in such a setting. As online asynchronous discussions are mostly conducted in a text-based format, typing and writing skills are demanding. Students who are weak in basic computer skills or online writing experience may have difficulty in typing large paragraphs of words (Hew \& Cheung, 2013). In the meantime, the lack of verbal cues and social-emotional experience can potentially create confusion in understanding the other's true meaning and reduce students' learning motivation and participation in collaborative online discussions (Cui et al., 2013; Hew \& Knapczyk, 2007; Yen \& Tu, 2008).

As learning in the online context has frequently transferred from a self-directed way to a collaborative pattern, the social aspect of learning should no longer be neglected. From the sociocultural perspective, knowledge is commonly socially constructed by collaborative work toward shared objectives or by discourses and challenges produced by differences in persons' perspectives (Vygotsky, 1978). Understanding, meaning, and knowledge gradually emerges through interaction and are distributed among those who interact (Pea, 1993). To better facilitate collaborative learning and knowledge construction, it is necessary to ensure and improve social interaction and collaboration among online learners. An important construct that has been developed and widely studied in relation to social interaction in online learning settings is social presence. Social presence refers to the degree of feeling, perception, and reaction of being connected by computer-mediated communication to another intellectual entity through electronic media (Tu \& McIsaac, 2002). Previous studies showed that a lack of social presence behaviors in online communication could cause a negative impact on the development of an online learning community (Garrison et al., 2000; Rovai, 2002), students' perceived learning and satisfaction (Gunawardena \& Zittle, 1997; Richardson \& Swan, 2003), and online interaction behaviors (Rourke et al., 1999; Tu \& McIsaac, 2002). Therefore, it is a key element in collaborative online learning environments.

To explore the affordances of online discussion technologies for the facilitation of online learners' interactions and collaborative learning, this study examines 
the use of two asynchronous tools for supporting online course discussion activities among a group of graduate students and investigates the differences in the levels of social presence and social knowledge construction using the two discussion tools. An associated goal is to identify how the students interact with others in computer-mediated communication through analyzing the types of online posts the students created and responded to others during discussions.

\section{Related literature}

\subsection{Social knowledge construction and social presence in online discussion settings}

The underlying theory behind utilizing online discussions for supporting students' learning and communication is social constructivism, which posits that knowledge is constructed through lived experiences and social interactions with others (Vygotsky, 1978). In online discussion activities, students typically need to discuss and negotiate with one another by writing and reading posts and are sometimes required to provide comments on other's posts in add-on threads (Sloan, 2015). This exchange of ideas and negotiation of meaning not only affects the individual's cognition, but the group's 'distributed cognition' as participants deliver, negotiate and transform their thoughts and create new knowledge as well (Salomon, 1993). In this manner, students not only acquire experiences and explanations from other peers and instructors, but can also pursue shared topics and goals which will be beneficial for sustainable learning and knowledge advancement (Scardamalia \& Bereiter, 2006).

Studies on social knowledge construction in online learning environments have long been the object of detailed investigation (De Wever et al., 2008; Hou \& Wu, 2011; Shukor et al., 2014). Previous research applied multiple methods to probe the process of social knowledge construction in online discussions (Lucas et al., 2014; Wise \& Chiu, 2011). By using the semi-automatic sequential analysis to work on a large sample of the discourse corpora, Weinberger and Fischer (2006) proposed a framework that can capture multiple process dimensions of collaborative learning and knowledge construction in CSCL. Hou and Wu (2011) examined the social knowledge construction behavioral patterns in learners' synchronous discussions with two analytical methods: the quantitative content analysis and the lag sequential analysis. Gunawardena et al. (2016) attempted to detect learners' social knowledge construction in online discussion forums using interaction analysis, learning analytics, and social network analysis techniques. The instrument they employed is the Interaction Analysis Model (IAM). The development of IAM was an attempt to interpret and describe the processes of negotiating meaning and knowledge coconstruction in a collaborative online discussion environment (Gunawardena et al., 1997). Types of knowledge construction activities can be represented by five phases (see Table 1): phase I-sharing and comparing information (includes observations, opinions, statements of agreement, and identifications of problems); phase IIdiscovering dissonance or inconsistency of ideas, concepts, or statements; phase III-negotiation of ideas or co-construction of knowledge; phase IV-testing and 


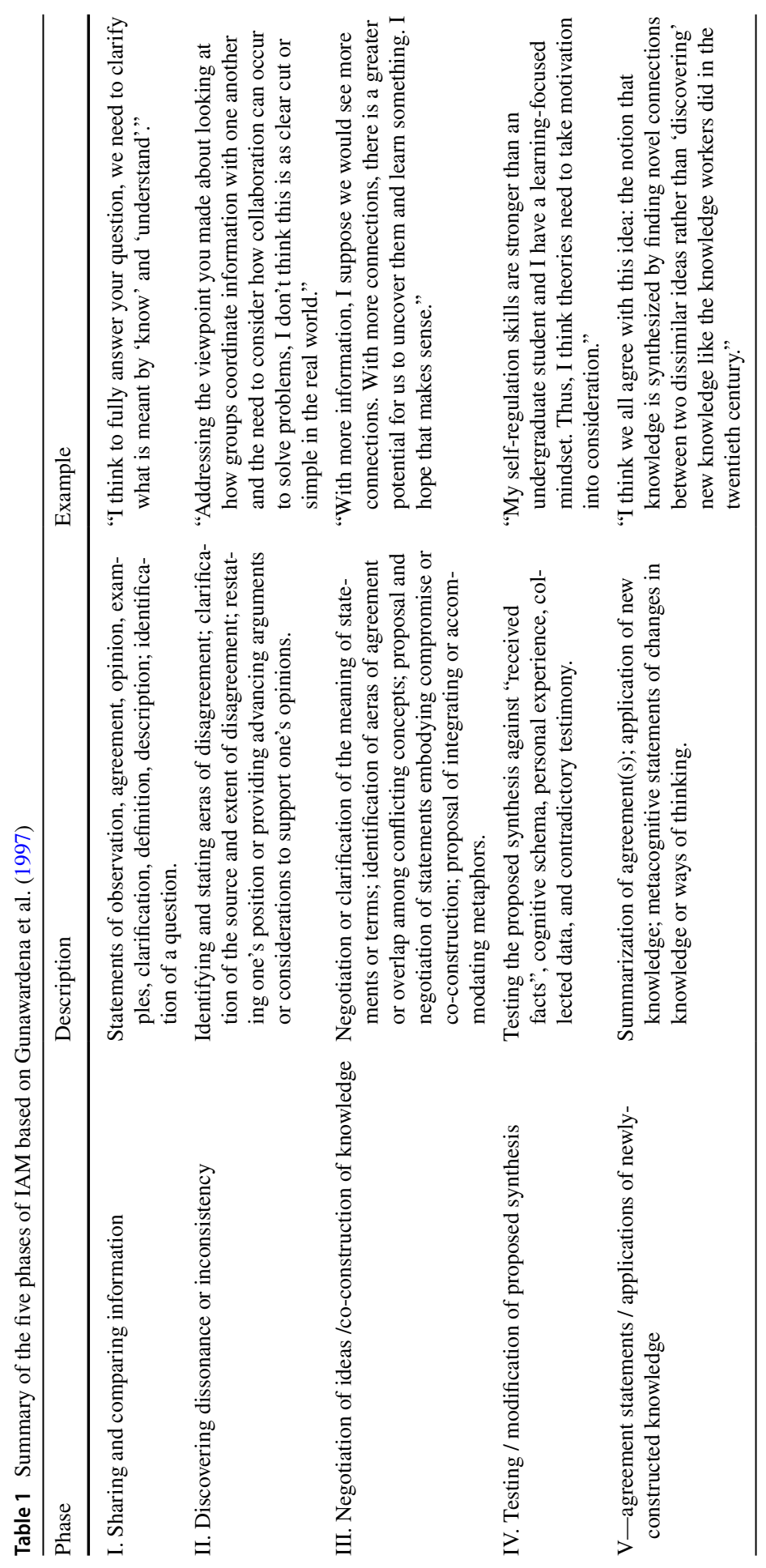


modification of proposed synthesis or co-construction; and phase $\mathrm{V}$-agreement statements or applications of newly-constructed knowledge. This final phase might consist of summarizing agreements, applications of new knowledge, and students' self-reflective statements that illustrate their knowledge or opinions have shifted as a result of the online discussion interaction (Hew \& Cheung, 2011). In this study, we employed the IAM for examining knowledge construction among online students for two reasons. First, this model is both theoretically and empirically grounded and attempts to capture "the complete process of negotiation" (Gunawardena et al., 1997) involved in knowledge construction, which normally occurs in online interactive discussions. Second, the phases of knowledge construction are relatively straightforward to evaluate (Lally, 2001) and therefore are suitable for the measurement of social knowledge construction processes in online discussions.

Another important concept that has been developed and widely studied in relation to social interaction in online learning settings is social presence. The first definition was proposed by Short et al. (1976) who first mentioned the concept of "social presence": "The degree of awareness of another person in an interaction and the consequent appreciation of an interpersonal relationship" (Short et al., 1976; Walther, 1992). Another definition was proposed by Garrison et al. (2000) as one of the three important elements of the Community of Inquiry (CoI) framework, which referred to "the ability of learners to project themselves socially and emotionally, thereby being perceived as 'real people' in mediated communication." (Garrison \& Arbaugh, 2007; Gunawardena \& Zittle, 1997). In online settings, social presence can be described as the degree of feeling emotionally connected to another intellectual through computer-mediated communication (Sung \& Mayer, 2012). Social presence has been found to have strong relationships with the development of an online learning community (Garrison et al., 2000; Rovai, 2002), students' perceived learning and satisfaction (Gunawardena \& Zittle, 1997; Richardson \& Swan, 2003), and online interaction behaviors (Rourke et al., 1999; Tu \& McIsaac, 2002).

As social presence is a critical indicator of both the medium and the communicators' perceptions of presence in a sequence of interactions (Gunawardena \& Zittle, 1997), the development of social presence measurement has been a key research focus that attracts the attention of researchers (Cui et al., 2013). As the foundational researchers in social presence, Short and colleges (Short et al., 1976) initially proposed the concept of social presence and developed a questionnaire measuring social presence using a semantic differential method. In order to test the impacts of video communication on social presence, De Greef and Ijsselsteijn (2001) constructed the IPO Social Presence Questionnaire (IPO-SPQ) questionnaire to assess social presence with telecommunication applications. Tu (2002) redefined three dimensions of social presence and developed the Social Presence and Privacy Questionnaire (SPPQ) to assess online users' perceptions of social presence and privacy in computer-mediated communication settings. Based on the method of content analysis, Rourke et al. (1999) proposed a social presence scheme, which was designed for assessing social presence cues in asynchronous text-based computer conferencing (Nippard \& Murphy, 2007). They identified three categories of communicative responses that contribute to social presence: affective responses, interactive responses, and cohesive responses. The affective responses include the expression 
of emotion, humor, and self-closure, while the interactive responses refer to a desire to initiate or maintain interaction with encouragement and acceptance. The cohesive category includes indicators of building or sustaining the sense of community by sharing personal information, addressing each other by names, and using inclusive pronouns (Garrison et al., 2000; Rourke et al., 1999). Realizing the insufficient emphasis on the emotional elements and some redundant indicators in this template, Hughes et al. (2007) conducted a replication study for assessing social presence in online discussion groups and made a few amendments to the Rourke et al.'s (1999) original template. The adapted coding template can be applied to reflect the emotional state of students' contributions in an online learning community. Based on the high level of fitness and reliability of the social presence scheme (Nippard \& Murphy, 2007) and our belief in the impact of emotional exchanges on the quality of online interaction and communication, we decided to use the adapted social presence coding template (Hughes et al., 2007) to code and analyze the levels of social presence in the online discussion activities among the participants (see Table 2).

\subsection{Technology utilization for online discussions}

Interaction and student cognitive engagement during online discussions are critical to constructing new understanding and knowledge (Galikyan \& Admiraal, 2019). Online discussions can take place with the assistance of different discussion tools, such as synchronous web conferencing technologies, asynchronous text-based discussion boards, and asynchronous audio/video-enhanced discussion methods (Clark et al., 2015; Hew \& Cheung, 2013). The synchronous communication technologies are dependent on time, and students and instructors need to present simultaneously in the online classroom for interaction opportunities (Ligorio, 2001). The online discussion board (ODB) is often utilized in both hybrid and fully online courses to offer a venue for students to communicate and build shared understanding, and for instructors to purposely facilitate the process (DeNoyelles et al., 2014). Its asynchronous and text-based features are favored by a certain number of online learners, as the ODB provides a learner-centered environment and sufficient time to raise questions, think, reflect, and respond to others' postings (Garrison et al., 2000; Havard et al., 2005; Pena-Shaff \& Nicholls, 2004).

Although the online discussion board allows individuals to discuss issues and topics at any time and from any geographical location, researchers argued that the online discussion board does not work well for all online learners (Clark et al., 2015; Girasoli \& Hannafin, 2008; Tu et al., 2010). Girasoli and Hannafin (2008) stated that text-based online discussion tools might potentially frustrate students who are uncomfortable with keyboards and allow fewer vocal students to engage in discussion activities, which can reduce the levels of social presence and negatively affect their interactions with others. Ward and Newlands (1998) contended that since textbased interactions occur in a disembodied form, the lack of nuance can easily result in a loss of meaning. Besides, it has been argued that text-based discussion is not sufficiently rich in the socially mediated practice that Vygotsky (1978) described as necessary to construct knowledge (Ice et al., 2007). 


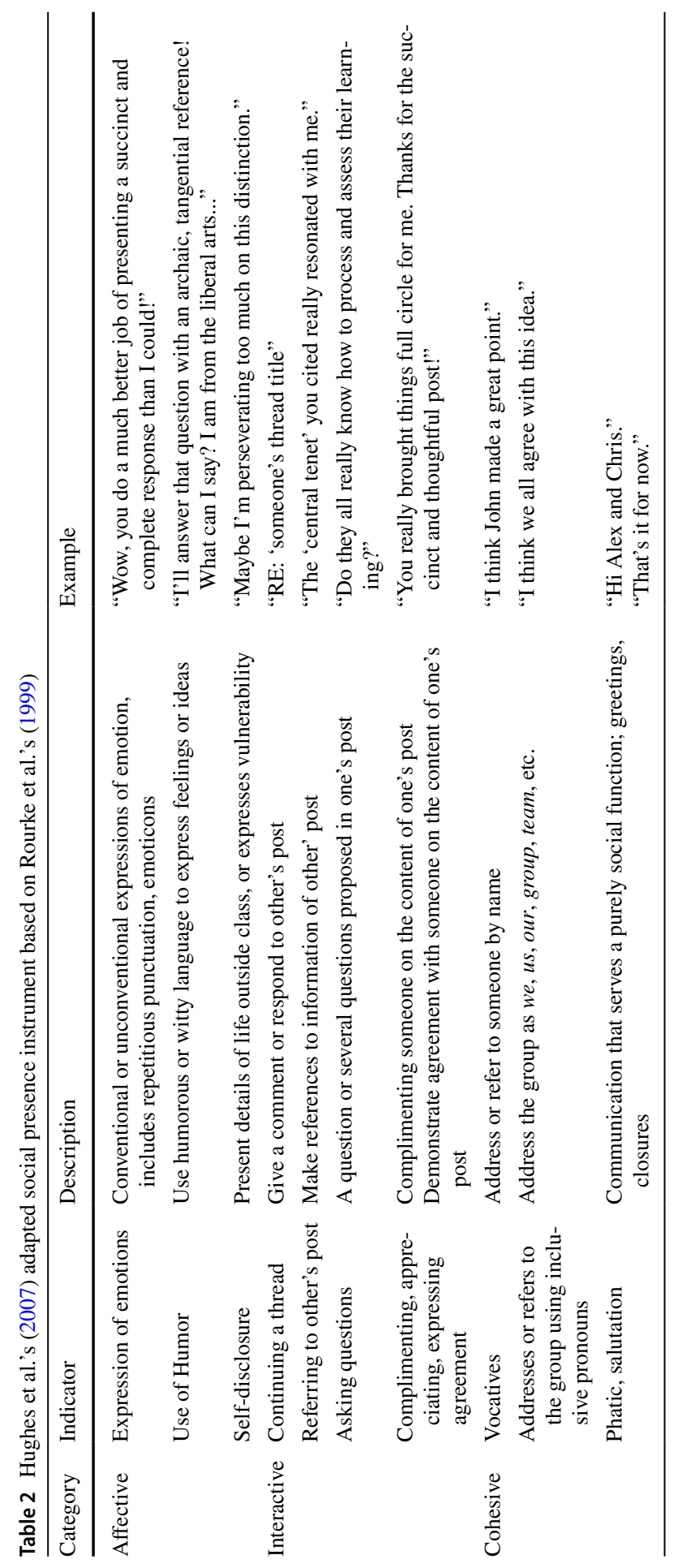


To cope with the drawbacks and explore the adoption of technology for online teaching and learning, researchers have attempted to integrate multimedia tools or other emerging technologies in the online environment to promote collaborative learning and discussions among students (Hew \& Cheung, 2013; Ligorio, 2001; Omar et al., 2012). Borup et al. (2012) believed that emerging audio or video technologies can promote interactions among students and thus more easily help foster the development of communities of inquiry. They collected three cases to demonstrate how instructors designed and taught courses through online asynchronous video tools and how the utilization of the tools influence students' perceptions of social presence. Many students stated that audio/video-enhanced communication made the instructors seem more real, present, and familiar than text-based discussion tools. Clark et al. (2015) realized that students may have feelings of isolation and may sometimes misunderstand others' meanings due to the lack of non-verbal social clues when they were discussing with classmates in the ODB. Therefore, they conducted a comparative study to examine whether a video-enhanced discussion platform would help create higher levels of teaching and social presence among a group of undergraduate students when compared with the text-based discussion platform. Reports and interviews from the students suggested that the video tools did provide a great sense of connection with others and helped students foster a community of inquiry. The quantitative results of social presence and teaching presence questionnaires also indicated that the participants who utilized the video-enhanced platform for the course discussion activities demonstrated higher perceptions of social and teaching presence than those using the text-based ODB. Oh and Kim (2016) contended that learners can only achieve higher-order thinking skills when they actually make cognitive efforts to engage deeply in online discussions. They designed scaffolded audio-based discussion activities using VoiceThread to promote students' cognitive engagement and perceived experiences. During the discussion activities, the participants generally had a high level of cognitive engagement and they demonstrated their preferences for the unique and useful benefits of audio as a discussion channel, such as liveliness in encouraging participation.

Although these studies highlighted the affordances of audio and video technology in enhancing online interaction and social presence, only a few attempted to examine the roles of audio or video discussion tools play in facilitating social knowledge construction among students during online discussion activities. This study plans to investigate whether VoiceThread has a positive influence on the facilitation of both students' levels of social presence and social knowledge construction. The following three research questions guided our study:

1) How did graduate students participate in online course discussion activities in the two online discussion settings?

2) What differences can be found in graduate students' social presence levels between the text-based online discussions and VoiceThread online discussions in an online course?

3) What differences can be found in graduate students' social knowledge construction between the text-based online discussions and VoiceThread online discussions in an online course? 


\section{Methods}

\subsection{Participants and research context}

After Institutional Review Board approval, we recruited a group of graduate students between the ages of 25 and 39 who enrolled in an online course that lasted one semester. All participants majored in education and came from a state university in the United States where the study was conducted. We emailed the students about the objectives of this study and obtained informed consent for participation. Ten students selected this course at the beginning of the semester, while two of them dropped out in the middle of the course. Finally, eight graduate students (five males and three females) completed the entire course procedure and consented to participate in this study. All were native English speakers so there were few language problems or barriers of expression during the interactions and the discussions. In addition, the participants had extensive experiences of learning and discussing in the online environments.

This study was carried out as part of an online graduate-level course and focused on analyzing student interactions and discussions through a universityprovided online learning management system - Blackboard. The main goals of this online course were to help students comprehend key themes and concepts in the field of online or distance learning and lead them to explore current issues and trends of educational research. The online course lasted for twelve weeks with five learning modules. Each learning module contains two discussion activities and other course-related tasks such as paper reading, essay writing, and artifact presentation. Prior to participate in the module discussion activities, the course instructor provided the students required reading materials and discussion guiding questions in the first section of each module. For this study, four discussion activities within two course learning modules were chosen as the primary data source. Two discussion activities in one learning module took place in the online discussion board (ODB) and the other two discussion activities in another learning module were designed and implemented with a multimedia tool - VoiceThread. Both discussion tools were accessible in the Blackboard learning system. VoiceThread (VT) is a multimedia communication platform used in any classroom setting including face-to-face or online (Delmas, 2017). Students and instructors can upload PowerPoints, images, videos, documents, or any other media source into VT to develop a slide-based presentation. When a discussant adds an audio or a video comment to a slide and decides to share the presentation, other discussants can give feedback through audio or video in the slide as well (Fox, 2017). In this study, the participants were encouraged to use audio/video recording features to create messages and add on others' posts in the discussion thread. The course requirements for each student to participate in each discussion activity using both tools included 1) create at least two posts that can demonstrate personal ideas or experiences based on the corresponding module topics or the guiding questions, 2) provide responding comments to at least two other students, 3) participate in and complete the above two requirements before each activity deadline. 


\subsection{Data collection and analysis}

This study mainly adopts a quantitative approach. The main data source was the online discussion posts generated by the participants in the text-based ODB and the VT platform on the Blackboard. Discourse in the online posts in both settings were recorded and transcribed for data analysis. To examine differences in the posting behaviors in two discussion settings, quantitative data including the total number of the posts and the average amount of words per post were counted as an important aspect reflecting students' participation in the course discussion activities at a general level. Discussion posts that demonstrate participants' feelings and attitudes toward the utilization of discussion tools were marked and selected for content analysis. In addition, Hewitt's (2002) four types of threaded discussion posts were adopted, which can provide insights into how online learners interact with others in computer-mediated communication settings. The four post types include: (1) Standalone posts (the post that introduces new ideas and does not build on other's posts), (2) add-on posts (quote or build on the ideas of one other post), (3) multiple reference posts (make reference to two or more previous posts with no attempts at convergence), and (4) convergent posts (the post that mentions some of the ideas stated in two or more others' posts). The quality and quantity of various types of online posts in the activity can demonstrate the way participants chose to discuss with others and the degree of social knowledge construction during the discussions.

As for the investigation of the participants' levels of social presence and social knowledge construction during the course discussion activities, a social presence coding template (Hughes et al., 2007) and the Interaction Analysis Model (Gunawardena et al., 1997) mentioned in the literature section were adopted for coding the transcripts of the discussion posts. Table 3 displays the sample online post excerpts in the two discussion settings. Two independent raters whose research field was online interactions analysis were responsible for the coding process. The inter-rater reliability calculated using the Cohen's Kappa coefficients were 0.87 for the social presence codes and 0.80 for the social knowledge construction codes. Since Cohen's Kappa values above 0.70 are generally considered satisfactory, the inter-rater reliability coefficients between the raters for advancing coding were acceptable. All disagreements were discussed and removed by the two raters and the researchers at a meeting after the completion of the coding process.

\section{Results}

\subsection{Participation and interaction patterns}

As student participation is one of the most influential features of online courses, this aspect is usually examined by counting the number of participants in each group, the number of messages, and the distribution of messages among group members. To take a close look at the students' participation and interaction in the discussion activities, the total number of the posts and the average number of words per discussion post were recorded (see Table 4). Additionally, to explore 


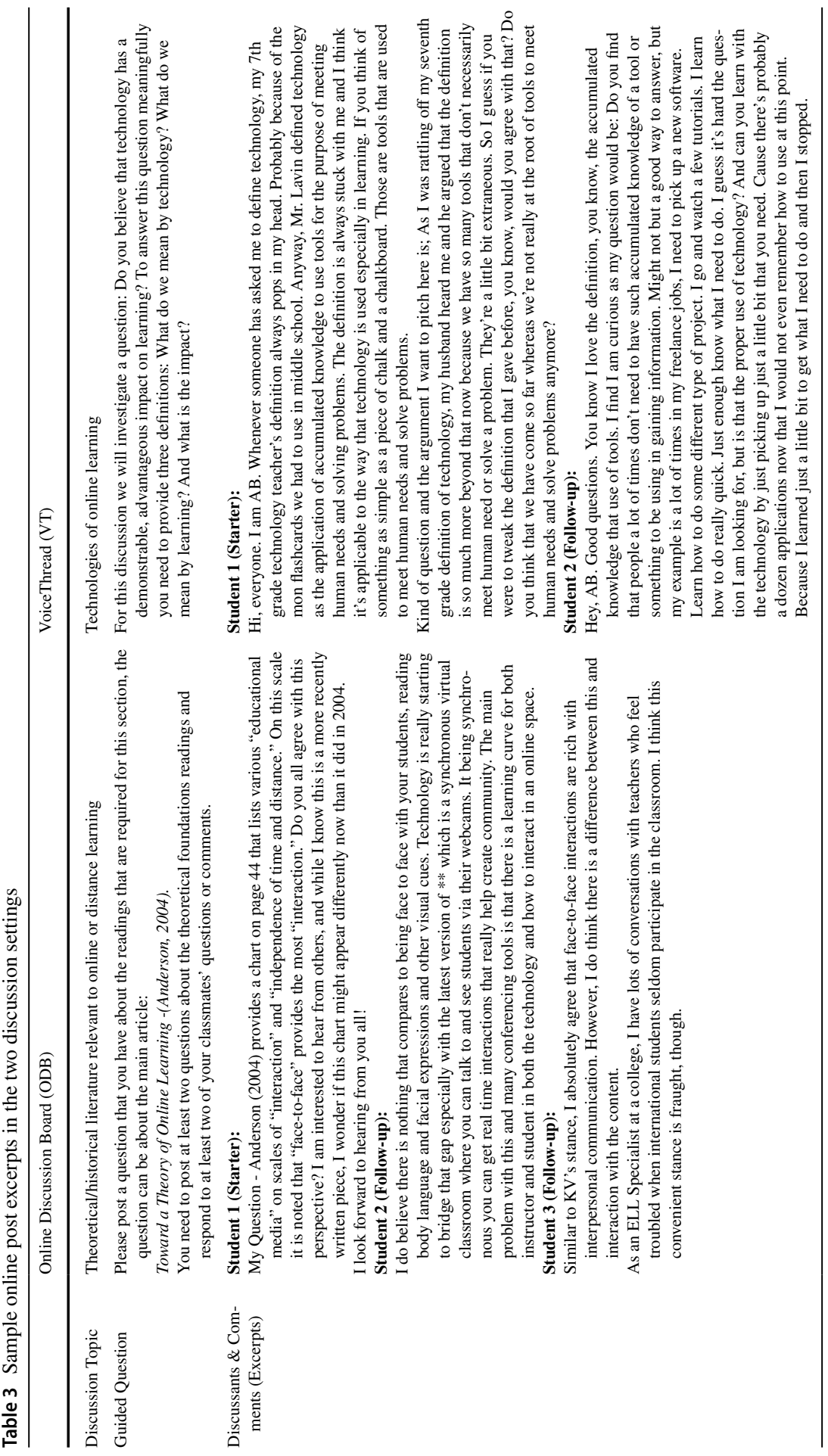


Table 4 Post total number, average length, and key information mentioned in the discussions

\begin{tabular}{llll}
\hline & $\begin{array}{l}\text { Total post } \\
\text { number }\end{array}$ & $\begin{array}{l}\text { Average words } \\
\text { amount per post }\end{array}$ & $\begin{array}{l}\text { Key concepts, ideas } \\
\text { or statements per } \\
\text { post }\end{array}$ \\
\hline ODB & 72 & 222.71 & 5.49 \\
VT & 44 & 402.45 & 6.52 \\
\hline
\end{tabular}

the content value and the pertinence of each discussion post, the average number of key concepts, ideas, or statements mentioned in the post that brought novel viewpoints to other students, or were tightly related to the module topics or the required readings were counted as well.

As the results show, when engaging in discussion activities in the VT platform, the participants contributed fewer posts. However, they tended to create or respond to other classmates with more words in VT discussion posts. In addition, when students utilized the VT for discussions, they include more messages that related to the corresponding module discussion topics and core knowledge, as indicated by the larger average number of key concepts, ideas, or statements mentioned per post. One possible explanation for the larger average number of words generated in each VT discussion post is that speaking takes less time and cognitive load than typing long paragraphs of words. As one student stated:

Sometimes it is easier to speak your mind rather than thinking about how to put it on the text. When you are writing or typing, you tend to be conscious about the formality of your discussion discourse, which can stifle your thoughts.

Participants also demonstrated their positive attitudes towards the utilization of VT for online collaborative discussions in general. As one of the participants stated in one of the posts:

Using an asynchronous tool like VoiceThread is fantastic since it gives me the ability to listen to a comment posted by a classmate, think it over and then I create a response.

Furthermore, to explore how the participants communicate and interact with others, Hewitt's (2001) four online post types were used to examine the discussion posts. Table 5 displays that while there were active interactions among the participants in both settings, only a few participants provide responses to multiple classmates in a single post, and they rarely produced a more sophisticated type of posts that tied together ideas and concepts from different sources. This finding is consistent with

Table 5 Number of post types in the two discussion settings

\begin{tabular}{llllll}
\hline & Standalone & Single & Multiple & Convergence & Total \\
\hline ODB & 17 & 51 & 2 & 2 & 72 \\
VT & 7 & 30 & 1 & 6 & 44 \\
\hline
\end{tabular}


that of Hewitt (2001), who found that most students make little effort to synthesize or summarize ideas from different posts during their conferencing sessions.

\subsection{Social presence in two discussion settings}

One of the main goals of this study is to investigate how the participants demonstrated social presence cues or behaviors during the interactions. We transcribed and analyzed the discussion posts in the two settings using Hughes et al.'s (2007) social presence coding template, which includes 11 indicators of social presence in affective, interactive, and cohesive categories (see Table 2). Table 6 details the number of the three categories of social presence indicators that were identified and coded in both settings. As indicated, the participants demonstrated more social presence behaviors in the VT discussion activities overall. Specifically, the participants tended to provide more emotional expressions (affective) and demonstrated a considerably higher level of group awareness (cohesive) when interacting in the VT platform, which can indicate the advantage of utilizing VT for presenting emotional status and sense of community when the participants took part in the collaborative discussion activities.

To eliminate potential influences by the number of posting words to the number of social presence indicators in the discussion discourse, an index of determining the level of social presence that involves a calculation was adopted. The index is called Social Presence Density (SPD), which was proposed in the study of Rourke et al. (1999) as well. SPD is an index representing a unit of social presence instances per 1000 words, and this measure can be used to indicate group differences without being affected by the frequency of postings (So, 2009). The formula for SPD is presented below. The total number of words transcribed from the ODB and VT discussions are 16,036 and 17,708, respectively. And the SPD index measures for the ODB discussions and the VT discussions are 34.30 and 43.65 per 1000 words, respectively. This is a notable difference when the participants interacted in the two discussion settings in terms of the frequency of social presence behaviors.

\subsection{Social knowledge construction in two discussion settings}

According to the Interaction Analysis Model (IAM), knowledge construction occurs in a series of successive (though not necessarily strictly sequential) phases that can be viewed as generally moving from lower to higher mental functions (Wise \& Chiu, 2011). Through the analysis of the transcripts of the online discussion posts, the

Table 6 Indicators of social presence in the two discussion settings

\begin{tabular}{llllll}
\hline & Affective & Interactive & Cohesive & Total & SPD \\
\hline ODB & 107 & 250 & 193 & 550 & 34.30 \\
VT & 161 & 239 & 373 & 773 & 43.65 \\
\hline$*$ SPD (Affective + & Interactive + Cohesive) & / Total Number of \\
Words * 1000 & &
\end{tabular}


Table 7 Distribution of each phase of IAM in the two discussion settings

\begin{tabular}{lllllll}
\hline & Phase 1 & Phase 2 & Phase 3 & Phase 4 & Phase 5 & Total \\
\hline ODB & $92(37.7 \%)$ & $54(22.1 \%)$ & $71(29.1 \%)$ & $19(7.8 \%)$ & $8(3.3 \%)$ & 244 \\
VT & $73(37.4 \%)$ & $33(16.9 \%)$ & $51(26.2 \%)$ & $18(9.2 \%)$ & $20(10.3 \%)$ & 195 \\
Total & $165(37.6 \%)$ & $87(19.8 \%)$ & $122(27.8 \%)$ & $37(8.4 \%)$ & $28(6.4 \%)$ & 439 \\
\hline
\end{tabular}

participants' level of social knowledge construction in both discussion settings was explored. Some interesting findings can be observed in Table 7. First, in the textbased online discussion board, the participants were involved in more social knowledge construction in the process of discussion and negotiation with others. One possible reason is that students require more time to structure and organize their posts and responses in the text format, which leads to more cognitive engagement and deeper knowledge processing. Second, the participants tended to construct and apply new knowledge more frequently when participating in VT discussion activities. This is evident in that there were a larger number of knowledge construction behaviors in Phase $\mathrm{V}$ with a lower total number of online posts. This can be explained by the fact that the audio or video posts enable students to communicate directly with each other and enter into the final agreement statements. Third, the participants were found to engage in testing the proposed new knowledge against the existing cognitive schema, personal experiences, or other sources (Phase IV) almost at the same level in the two discussion platforms. Moreover, more than $85 \%$ of social knowledge construction behaviors were detected in the first three phases across all the four discussion activities, which suggests that the participants were mostly involved in sharing and comparing their thoughts with others (Phase I), identifying dissonances or inconsistencies among different ideas and opinions (Phase II), and negotiating and co-constructing knowledge during the discussion period (Phase III).

\section{Discussion and conclusion}

Learning is increasingly seen to be embedded in social interaction and participation in online discussions can facilitate the performance of collaborative learning to achieve better results (Xia et al., 2013). This study explored how graduate students participate and interact during text-based (ODB) and audio/video-enhanced (VT) online course discussion activities. The frequency of posting that quantitatively captures student participation level and the average number of words per post in the two discussion settings were recorded. The results outlined above show that although the participants generated fewer discussion posts in the VT settings, they tended to contribute more words when using the audio and video features, which reflects their active participation in online discussion activities. Although participation is an important factor that can affect student motivation and performance in online learning (Martin \& Bolliger, 2018), it is not sufficient to guarantee quality interaction and knowledge construction (An et al., 2009; Heo et al., 2010). Therefore, we also 
counted the average number of key concepts, ideas, or statements mentioned in the online posts that can bring new perspectives or were pertinent to the discussion topics or learning materials. The slightly higher number in this dimension of the VT discussions indicates the participants were more focused on shared topics and tasks when creating and responding to others with audio or video comments.

The findings of this study also contribute to better understandings of how the use of different online discussion tools exerts an effect on students' levels of social presence and social knowledge construction. First, the participants engaged in meaningful discussions and interactions with others in both discussion settings, as can be seen from the high frequency of quoting or building on the ideas of one other post. One thing to notice is that although the participants generated a limited number of convergent posts, and they rarely advance to the higher knowledge construction phases (co-construction against the existing cognitive schema, personal experiences, or literature, and summarizing the newly-constructed knowledge), it does not necessarily mean that these participants have low levels of critical thinking and summarizing skills. Previous research suggested that assigning some summarizing roles or tasks in the process of discussions can help the group progress toward more advanced phases of knowledge construction (Wise \& Chiu, 2011). The summarizing activity was not required in this course, but future research might include this aspect. Second, although the students demonstrated a higher social presence level when editing audio or video posts, we can't simply draw the conclusion that discussing in the ODB limited the generation of social presence among the students. In fact, previous researchers detected a considerable number of indicators of social presence among students in text-based discussion environments (Gunawardena \& Zittle, 1997; Richardson \& Swan, 2003; Rourke et al., 1999; Tu \& McIsaac, 2002). Therefore, the importance of the use of asynchronous text-based online discussion boards or forums to help enhance students' collaborative inquiry, online communication, and knowledge construction should not be overlooked or underestimated. Third, although the participants were found to be involved in social knowledge construction less frequently in VT than they were in the ODB, they tended to form more consensuses in the process of negotiation and applied the newly-constructed knowledge more frequently when they can hear or watch others' voices or postures in the VT posts, as indicated by the number of the indicators identified as the fifth phase of IAM. A possible explanation may be that the audio or video comments make it easy for students to communicate with each other and reach final agreements. Hew and Cheung (2013) also highlighted that asynchronous audio or video discussions can promote a greater understanding of posted messages and help learners to reach consensuses. Finally, different from previous studies which emphasized instructor's support and participation in online discussions (Dalelio, 2013; Martin \& Bolliger, 2018; Tibi, 2018), the design of this course's discussion activities were primarily learner-centered and focused on student-to-student interaction. We believe that the two asynchronous online discussion tools can provide ideal environments for the social constructivist mode of learning, where the students can actively and autonomously negotiate and construct meanings in the social context (Gao, 2014; Oztok et al., 2013). 
There are some limitations within this study. First, this study contains only a small amount of data generated by a limited number of graduate students. The online course in this study was an elective for graduate students of the College of Education. Ten students chose this course and two of them dropped out in the middle of the course. Only eight students completed all discussion activities and consented to participate in this study. Therefore, the sample of graduate-level students limits its generalizability to other online or blended learning contexts. Future studies should make attempts to incorporate a larger sample size and include students from various majors and grades to obtain a better understanding of collaborative learning, social presence, and knowledge construction in different online discussion settings. Second, a few pieces of discussion discourses in audio format could not be transcribed due to the issues with recording equipment on the student side. Fortunately, there were only a small number of missing words in three individual posts that were marked as inaudible and had insignificant effects on the results. Third, this study mainly adopted a quantitative approach to analyze student differences in online discussion discourses. More qualitative approaches should be considered in future studies as these can provide in-depth analysis in more specific perspectives. For example, what types of online posts can exert a great impact on students' social presence levels and social knowledge construction, how the levels of social presence change in the process of online discussions, and what are the temporal patterns of social knowledge construction in different types of collaborative online discussions.

Open Access This article is licensed under a Creative Commons Attribution 4.0 International License, which permits use, sharing, adaptation, distribution and reproduction in any medium or format, as long as you give appropriate credit to the original author(s) and the source, provide a link to the Creative Commons licence, and indicate if changes were made. The images or other third party material in this article are included in the article's Creative Commons licence, unless indicated otherwise in a credit line to the material. If material is not included in the article's Creative Commons licence and your intended use is not permitted by statutory regulation or exceeds the permitted use, you will need to obtain permission directly from the copyright holder. To view a copy of this licence, visit http://creativecommons.org/licen ses/by/4.0/.

\section{References}

Allen, I. E., Seaman, J., Poulin, R., \& Straut, T. T. (2016). Online report card: Tracking online education in the United States. Babson Survey Research Group and Quahog Research Group. Retrieved from Online Learning Consortium: https://onlinelearningconsortium.org/survey_report/2015-onlinereport-card-tracking-online-education-united-states/. Accessed Feb 2016.

An, H., Shin, S., \& Lim, K. (2009). The effects of different instructor facilitation approaches on students' interactions during asynchronous online discussions. Computers \& Education, 53(3), 749-760.

Borup, J., West, R. E., \& Graham, C. R. (2012). Improving online social presence through asynchronous video. The Internet and Higher Education, 15(3), 195-203.

Clark, C., Strudler, N., \& Grove, K. (2015). Comparing asynchronous and synchronous video vs. textbased discussions in an online teacher education course. Online Learning Journal, 19(3), 48-69.

Cui, G., Lockee, B., \& Meng, C. (2013). Building modern online social presence: A review of social presence theory and its instructional design implications for future trends. Education and Information Technologies, 18(4), 661-685. 
Dalelio, C. (2013). Student participation in online discussion boards in a higher education setting. International Journal on E-Learning, 12(3), 249-271.

De Greef, P., \& Ijsselsteijn, W. A. (2001). Social presence in a home tele-application. CyberPsychology and Behavior, 4(2), 307-315.

De Wever, B., Schellens, T., Van Keer, H., \& Valcke, M. (2008). Structuring asynchronous discussion groups by introducing roles: Do students act up to the assigned roles? Small Group Research, 39(6), $770-794$.

Delmas, P. M. (2017). Using VoiceThread to create community in online learning. Techtrends: Linking Research and Practice to Improve Learning, 61(6), 595-602.

DeNoyelles, A., Zydney, J., \& Chen, B. (2014). Strategies for creating a community of inquiry through online asynchronous discussions. Journal of Online Learning and Teaching, 10(1), 153-165.

Fox, O. (2017). Using VoiceThread to promote collaborative learning in on-line clinical nurse leader courses. Journal of Professional Nursing, 33(1), 20-26.

Galikyan, I., \& Admiraal, W. (2019). Students' engagement in asynchronous online discussion: The relationship between cognitive presence, learner prominence, and academic performance. The Internet and Higher Education, 43, 1-9.

Gao, F. (2014). Exploring the use of discussion strategies and labels in asynchronous online discussion. Journal of Asynchronous Learning Network, 18(3), 1-19.

Gao, F., Zhang, T., \& Franklin, T. (2013). Designing asynchronous online discussion environments: Recent progress and possible future directions. British Journal of Educational Technology, 44(3), 469-483.

Garrison, D. R., \& Arbaugh, J. B. (2007). Researching the community of inquiry framework: Review, issues, and future directions. The Internet and Higher Education, 10(3), 157-172.

Garrison, D. R., Anderson, T., \& Archer, W. (2000). Critical inquiry in a text-based environment: Computer conferencing in higher education. The Internet and Higher Education, 2(2), 87-105.

Girasoli, A. J., \& Hannafin, R. D. (2008). Using asynchronous AV communication tools to increase academic self-efficacy. Computers \& Education, 51(4), 1676-1682.

Gunawardena, C., \& Zittle, F. (1997). Social presence as a predictor of satisfaction within a computer mediated conferencing environment. American Journal of Distance Education, 11(3), 8-26.

Gunawardena, C., Lowe, C., \& Anderson, T. (1997). Analysis of a global online debate and the development of an interaction analysis model for examining social construction of knowledge in computer conferencing. Journal of Educational Computing Research, 17(4), 397-431.

Gunawardena, C. N., Flor, N. V., Gómez, D., \& Sánchez, D. (2016). Analyzing social construction of knowledge online by employing interaction analysis, learning analytics, and social network analysis. Quarterly Review of Distance Education, 17(3), 35-60.

Havard, B., Du, J., \& Olinzock, A. (2005). Deep learning: The knowledge, methods and cognition process in instructor-led online discussion. Quarterly Review of Distance Education, 6(2), 125-135.

Heo, H., Lim, K. Y., \& Kim, Y. (2010). Exploratory study on the patterns of online interaction and knowledge co-construction in project-based learning. Computers \& Education, 55(3), 1383-1392.

Hew, K. F., \& Cheung, W. S. (2011). Higher-level knowledge construction in asynchronous online discussions: An analysis of group size, duration of online discussion, and student facilitation techniques. Instructional Science, 39(3), 303-319.

Hew, K. F., \& Cheung, W. S. (2013). Audio-based versus text-based asynchronous online discussion: Two case studies. Instructional Science, 41(2), 365-380.

Hew, K. F., \& Knapczyk, D. (2007). Analysis of ill-structured problem solving, mentoring functions, and perceptions of practicum teachers and mentors toward online mentoring in a field-based practicum. Instructional Science, 35(1), 1-40.

Hewitt, J. (2001). Beyond threaded discourse. International Journal of Educational Telecommunications, $7(3), 207-221$.

Hou, H. T., \& Wu, S. Y. (2011). Analyzing the social knowledge construction behavioral patterns of an online synchronous collaborative discussion instructional activity using an instant messaging tool: A case study. Computers \& Education, 57(2), 1459-1468.

Hughes, M., Ventura, S., \& Dando, M. (2007). Assessing social presence in online discussion groups: A replication study. Innovations in Education and Teaching International, 44(1), 17-29.

Ice, P., Curtis, R., Phillips, P., \& Wells, J. (2007). Using asynchronous audio feedback to enhance teaching presence and students' sense of community. Journal of Asynchronous Learning Networks, 11(2), $3-25$. 
Johnson, G. (2008). The relative learning benefits of synchronous and asynchronous text-based discussion. British Journal of Educational Technology, 39(1), 166-169.

Lally, V. (2001). Analysing teaching and learning interactions in a networked collaborative learning environment: Issues and work in progress. In P. Dillenbourg, A. Eurelings, \& K. Hakkarainen (Eds.), European perspectives on CSCL (pp. 397-405). Maastricht McLuhan Institute.

Levine, S. J. (2007). The online discussion board. New Directions for Adult and Continuing Education, $113,67-74$

Ligorio, M. B. (2001). Integrating communication formats: Synchronous versus asynchronous and textbased versus visual. Computers \& Education, 37(2), 103-125.

Lucas, M., Gunawardena, C., \& Moreira, A. (2014). Assessing social construction of knowledge online: A critique of the interaction analysis model. Computers in Human Behavior, 30, 574-582.

Martin, F., \& Bolliger, D. U. (2018). Engagement matters: Student perceptions on the importance of engagement strategies in the online learning environment. Online Learning Journal, 22(1), 205-222.

Nippard, E., \& Murphy, E. (2007). Social presence in the web-based synchronous secondary classroom. Canadian Journal of Learning and Technology, 33(1). Retrieved from http://www.cjlt.ca/index.php/ cjlt/article/view/24/22.

Oh, E. G., \& Kim, H. S. (2016). Understanding cognitive engagement in online discussion: Use of a scaffolded, audio-based argumentation activity. The International Review of Research in Open and Distributed Learning, 17(5), 28-48.

Omar, H., Embi, M. A., \& Yunus, M. M. (2012). ESL learners' interaction in an online discussion via facebook. Asian Social Science, 8(11), 67-74.

Oztok, M., Zingaro, D., Brett, C., \& Hewitt, J. (2013). Exploring asynchronous and synchronous tool use in online courses. Computers \& Education, 60(1), 87-94.

Pea, R. D. (1993). Practices of distributed intelligence and designs for education. In G. Salomon (Ed.), Distributed cognitions: Psychological and educational considerations (pp. 47-87). Cambridge University Press.

Pena-Shaff, J. B., \& Nicholls, C. (2004). Analyzing student interactions and meaning construction in computer bulletin board discussions. Computers \& Education, 42(3), 243-265.

Richardson, J. C., \& Swan, K. (2003). Examining social presence in online courses in relation to students' perceived learning and satisfaction. Journal of Asynchronous Learning Networks, 7(1), 68-88.

Rourke, L., Anderson, T., Garrison, D. R., \& Archer, W. (1999). Assessing social presence in asynchronous text-based computer conferencing. Journal of Distance Education, 14(3), 51-70.

Rovai, A. P. (2002). Development of an instrument to measure classroom community. The Internet and Higher Education, 5(3), 197-211.

Salomon, G. (1993). No distribution without individuals' cognition: A dynamic interactional view. In G. Salomon (Ed.), Distributed cognition: Psychological and educational considerations (pp. 111-138). Cambridge University Press.

Scardamalia, M., \& Bereiter, C. (2006). Knowledge building: Theory, pedagogy, and technology. In R. K. Sawyer (Ed.), The Cambridge handbook of the learning sciences (pp. 97-118). Cambridge University Press.

Shea, P., Gozza-Cohen, M., Uzuner-Smith, S., Mehta, R., Valtcheva, A. V., Hayes, S., \& Vickers, J. (2011). The community of inquiry framework meets the SOLO taxonomy: A process-product model of online learning. Educational Media International, 48(2), 101-113.

Short, J., Williams, E., \& Christie, B. (1976). The social psychology of telecommunications. Wiley.

Shukor, N. A., Tasir, Z., Van der Meijden, H., \& Harun, J. (2014). Exploring students' knowledge construction strategies in computer-supported collaborative learning discussions using sequential analysis. Journal of Educational Technology and Society, 17(4), 216-228.

Sloan, C. (2015). The relationship of high school student motivation and comments in online discussion forums. Journal of Educational Computing Research, 52(1), 114-135.

So, H. J. (2009). When groups decide to use asynchronous online discussions: Collaborative learning and social presence under a voluntary participation structure. Journal of Computer Assisted Learning, 25(2), 143-160.

Sung, E., \& Mayer, R. E. (2012). Five facets of social presence in online distance education. Computers in Human Behavior, 28(5), 1738-1747.

Thomas, J. (2013). Exploring the use of asynchronous online discussion in health care education: A literature review. Computers \& Education, 69, 199-215. 
Tibi, M. H. (2018). Computer science students' attitudes towards the use of structured and unstructured discussion forums in fully online courses. Online Learning Journal, 22(1), 93-106.

Tu, C. H. (2002). The measurement of social presence in an online learning environment. International Journal on e-Learning, 1(2), 34-45.

Tu, C. H., \& McIsaac, M. (2002). The relationship of social presence and interaction in online classes. American Journal of Distance Education, 16(3), 131-150.

Tu, C. H., Blocher, M., \& Gallagher, L. (2010). Asynchronous network discussions as organizational scaffold learning: Threaded vs. flat-structured discussion boards. Journal of Educational Technology Development and Exchange, 3(1), 43-56.

Vygotsky, L. S. (1978). Mind in society. Harvard University Press.

Walther, J. B. (1992). Interpersonal effects in computer-mediated interaction: A relational perspective. Communication Research, 19(1), 52-90.

Ward, M., \& Newlands, D. (1998). Use of the web in undergraduate teaching. Computers \& Education, 31(2), 171-184.

Weinberger, A., \& Fischer, F. (2006). A framework to analyze argumentative knowledge construction in computer-supported collaborative learning. Computers \& Education, 46(1), 71-95.

Wise, A. F., \& Chiu, M. M. (2011). Analyzing temporal patterns of knowledge construction in a rolebased online discussion. International Journal of Computer-Supported Collaborative Learning, $6(3), 445-470$.

Xia, J., Fielder, J., \& Siragusa, L. (2013). Achieving better peer interaction in online discussion forums: A reflective practitioner case study. Issues in Educational Research, 23(1), 97-113.

Yen, C. J., \& Tu, C. H. (2008). Online social presence: A study of score validity of the computer-mediated communication questionnaire. Quarterly Review of Distance Education, 9(3), 297-310.

Publisher's note Springer Nature remains neutral with regard to jurisdictional claims in published maps and institutional affiliations. 